\title{
Traumatic Degloving Injury of Penile and Scrotal Skin: A Case Report and Review of Literature
}

\author{
Saadallah M. Al-Zacko ${ }^{1}$, Ayman S. Mohammad ${ }^{2}$ and Ameer S. Al-Zacko ${ }^{2}$ \\ 1. Plastic Surgery, College of Medicine, University of Mosul, Mosul 41001, Iraq \\ 2. Plastic Surgery, Al-Jumhoori Teaching Hospital, Mosul 41001, Iraq
}

\begin{abstract}
Degloving injuries of penile and scrotal skin are uncommon events and are caused mainly by accidents with industrial and agricultural machine belts. Here we report a young male who presented shortly after a farm machinery injury to his genitalia resulting in a degloving injury of his penile and scrotal skin. Optimization of the wound and subsequent reconstruction were performed by primary meshed split-thickness skin grafting, with a good functional and esthetical result.
\end{abstract}

Key words: Penile, scrotal, degloving injuries, split-thickness skin graft (STSG).

\section{Introduction}

Degloving injury of the male genitals is an uncommon urological presentation [1-3]. They occur mainly following industrial or agricultural machinery accidents involving loose clothing that is rapidly and forcefully torn from the victim [4].

As the genitalia are mobile and testicles are protected by tunica albuginea and cremasteric reflex, wounds can only reach the skin causing minimal bleeding without damaging cavernous bodies, the spongy body, or testes $[3,5,6]$.

Extensive scrotal wounds with exposed testes represents challenging problems to the reconstructive surgeons. Although not life-threatening, such lesions are incapacitating and have a devastating psychological impact if not treated properly [1]. They should be treated as surgical emergencies with early skin grafting to prevent infection and avoid subsequent complications.

\section{Case Report}

A 33-year-old man was working in a farm sustained

Corresponding author: Saadallah M. Al-Zacko, professor, research fields: plastic surgery (all field especially rhinoplasty $\&$ cleft lip / palate) \& burns. a degloving injury to his genitalia when his clothes were caught in a harvesting machine pulley from which the safety guard had been removed. He received the initial management at a peripheral health center including tetanus toxoid, analgesia, intravenous fluids, light dressing and intravenous antibiotics. He arrived to Al-Jumhoori Teaching Hospital approximately 2 hours after the trauma.

At the Emergency Department he was awake, haemodynamically stable with a degloving injury involving the near-total shaft of the penis and the whole scrotum, with exposure of testes and shaft of penis. Bilateral testes and epididymis were only connected by spermatic cord (Fig. 1).

The patient was admitted, and the investigations ordered including complete blood count, coagulation profile, urine analysis and renal functions tests revealed no abnormality. Wound swab was taken for culture and sensitivity. Ultrasound indicated the erectile tissues, urethra, and testes were not damaged.

After introducing a urinary catheter for intermittent bladder drainage, careful debridement of the devitalised tissue and removal of dirt were done under general anaesthesia, and assessment of the extent of penile damage and confirming the viability of the testicles. 


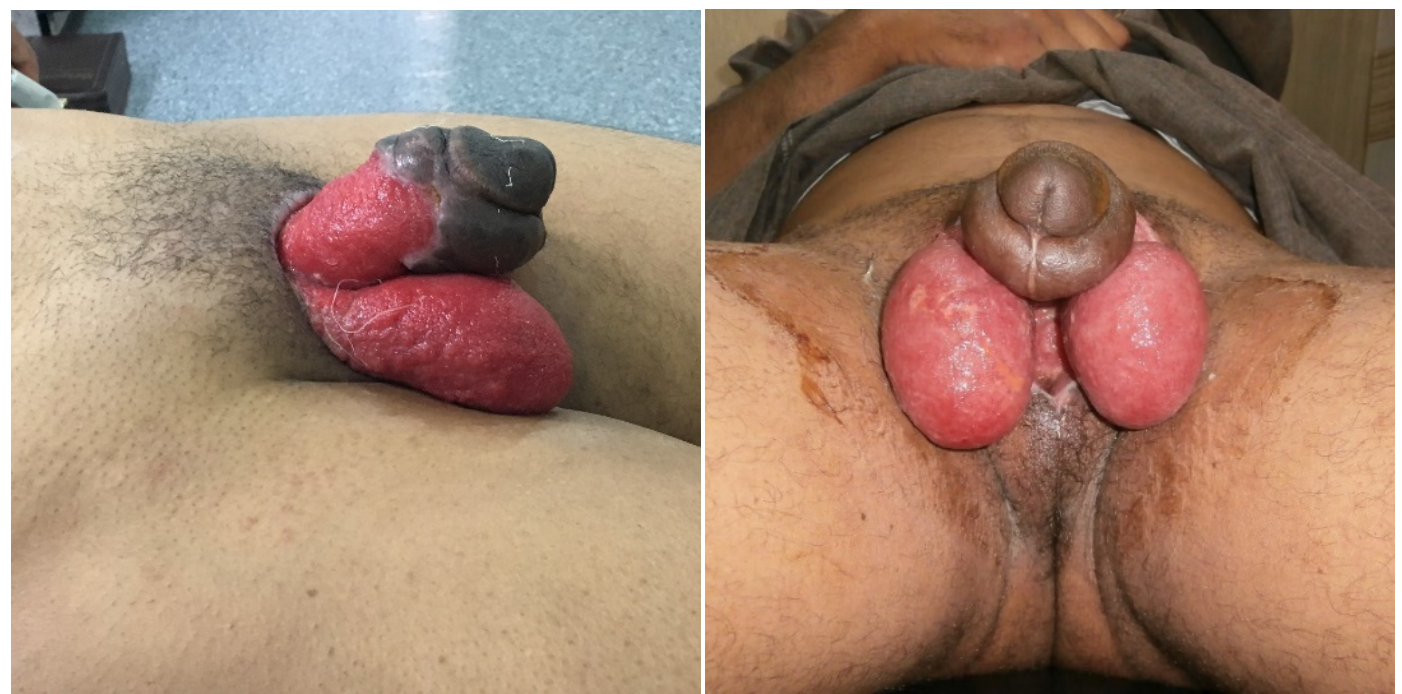

Fig. 1 Degloving injury of penis and scrotum.

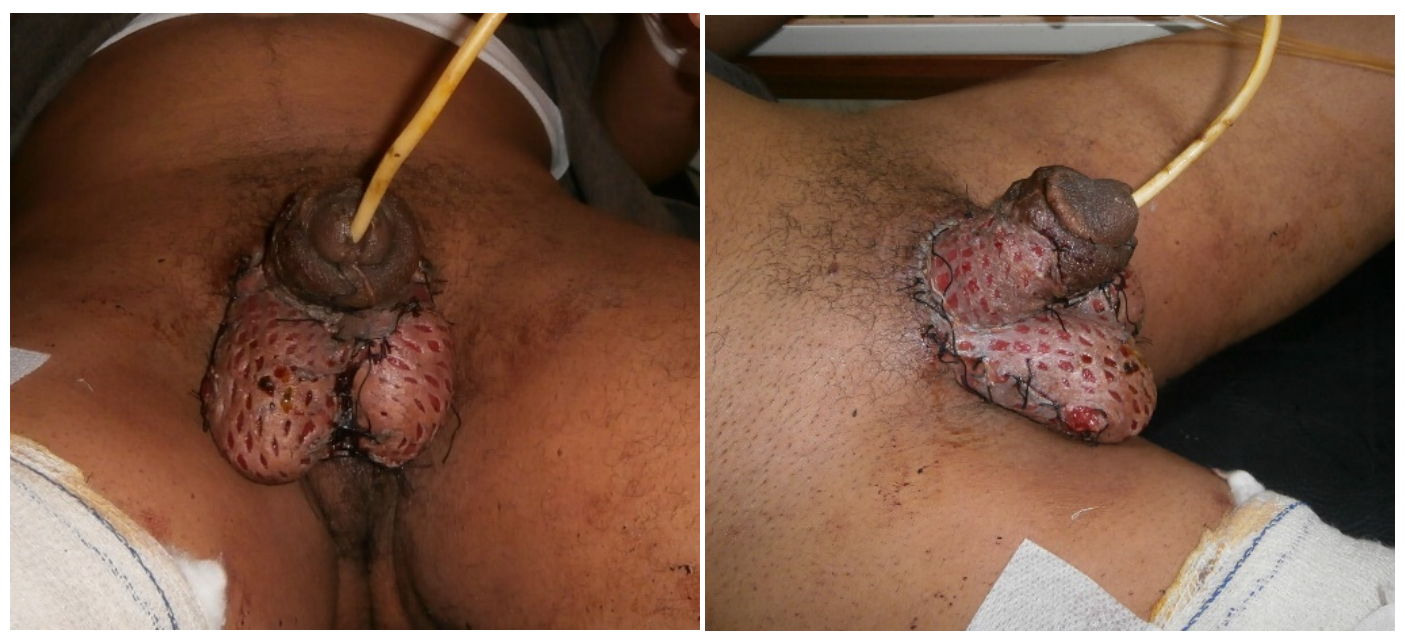

Fig. 2 Five days after surgery, graft take was optimal on the penis and scrotum.

Then the patient subjected to regular twice-daily dressing with $4 \%$ povidone-iodine gauze compresses and continued on injectable piperacillin $4 \mathrm{~g} \mathrm{q} 8 \mathrm{~h}$ was administered until it was clean, healthy with no growth on culture.

On the day 7, with the patient under general anaesthesia, the wound was thoroughly washed with chlorhexidine soap, sodium chloride, and 4\% povidone-iodine solution. Then a $0.3 \mathrm{~mm}(12 / 1,000$-in) split skin graft is harvested from right medial thigh, meshed 1:1.5 and kept over the penile shaft and the testes after suturing them in the midline by $5 / 0$ vicryl. Five days later the dressing changed, the graft take was close to $100 \%$ and there were no signs of infection or hematoma (Fig. 2). His postoperative period was uneventful, with antibiotics being the mainstay of therapy. The penile and scrotal graft dressing were changed on post-operative days 5, 7, 9 and sutures and the indwelling catheter were removed on day 10 . Patient was discharged two weeks after surgery with ciprofloxacin, $500 \mathrm{mg}$, per os (PO) q12 h for 14 days, and with regular controls in out-patient clinic.

Six weeks after the last procedure, the patient recovered regular sexual activity and he was satisfied with this result (Fig. 3). However, he reported painful erections due to cicatricial retraction of the grafted skin. He had no complains about the size, shape or sensation of penis. Thus he is psychologically happy and the penile 


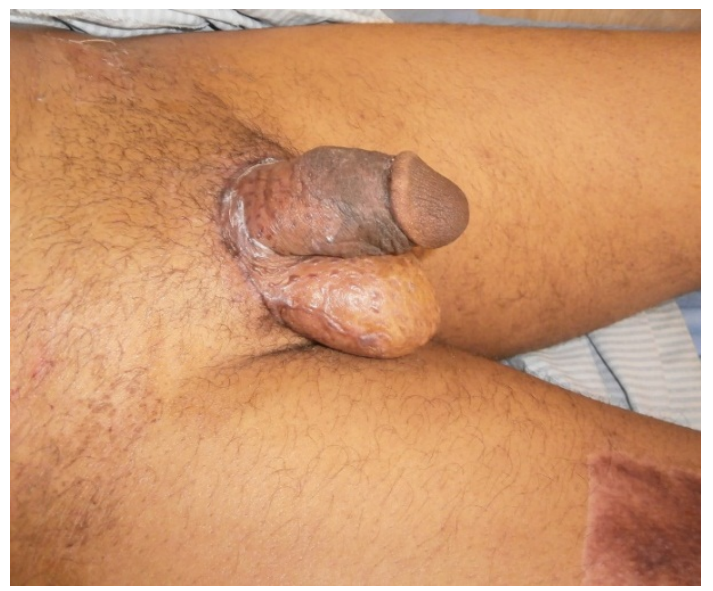

Fig. 3 Degloving injury single stage treatment-final outcome, 3 months postoperatively.

erection is slowly attaining the pre-injury size in three months.

\section{Discussion}

Degloving injuries of the penis and scrotum are rarely, if ever, life-threatening. However, the psychological burden inflicted on male patients by this type of injuries is so great, that they require increased attention and care by the doctor [3]. These injuries usually due to harvesting machines in agriculture field, industrial machines such as pulleys, chains and rotary discs. In these accidents loose clothes become caught in a rotating machine and the skin of male genitalia is torn off by torsion and traction $[1,3,7]$. The skin is usually torn at the scrotum, dragging the skin overlay from the base of the penis while the connection with the coronal sulcus remains intact.

The use of loose clothing materials like baggy trousers or thawb (an ankle-length garment worn by Arabian men), as in our case, has been associated with the incidence of industrial and/or agricultural machine parts snagging these and pulling out the penile and scrotal skin [1, 8]. Close-fitting workman clothing materials, like jeans, are less likely to be so snagged. Males of adult and adolescent age group are the usual victims [7-9].

Gibbs [10] was the first surgeon to successfully repair the defect following traumatic avulsion of the scrotum and penis and Kubacek [11] presented the first case report of this type of injury.

Generally, injuries damage only the skin, causing minimal bleeding without producing damage to the cavernous body, the spongy body or the testes because the avulsion takes place in a relatively avascular plane $[3,5,11]$. Testicular sparing is the rule with this injury, as in our case, and the cremasteric reflex has been implicated as a cause [12].

Penile examination should assess corporal integrity and should include inspection of the urethral meatus for blood that may indicate urethral injury. A completely intact tunica albuginea is the only finding that can preclude scrotal exploration.

Once total or near-total peno-scrotal skin loss has occurred, there are several reconstructive management options: split-thickness skin grafts (STSG), full-thickness skin grafts (FTSG), or a variety of myocutaneous or fasciocutaneous flaps [13-16]. STSG is a preferable alternative by many authors $[3,7,17$, $18]$.

The technique is not new and many authors have reported excellent results with split-skin grafts [19-22]. In the present case the injury was treated with a single staged procedure by split-skin grafting. The exposed testes are sutured together with fascia to make one mass over which a split-skin graft is laid. This prevents testicular torsion and allows for the appearance of a bifid, natural-appearing scrotum (Fig. 3). The split-thickness skin graft should be harvested from a 
relatively hairless area, such as the thigh.

Traditionally, grafts were held in-place post-operatively with bolstered dressings, commonly using petroleum-based gauze directly over the graft site. During this period, patients should be on strict bed-rest to prevent disruption of the graft during its most vulnerable period. At the three months follow up the patient who expressed satisfaction with both cosmetic and functional results.

Split-thickness skin graft is safe, well-tolerated and efficient in the reconstruction of penoscrotal defects [23]. This technique is simple, does not involve multistage procedures and can be done by relatively inexperienced surgeons. It provides good elasticity, flexibility, sub-abdominal temperatures for spermatogenesis, offers a more natural appearance of the scrotum, results in minimal post-operative morbidity, and can often be performed in a single stage [24]. There were added advantages of a one-step procedure with early return to normal lifestyle without any psychological problems.

Testicular burial in medial thigh pockets has long been abandoned due to the associated pain, testicular atrophy, negative effect on spermatogenesis and endocrine function $[25,26]$. In addition, staged operations like that described by Zanettini et al. [27] which extend to 7 months may have emotional impact on the patient, which we aim to minimize without jeopardizing the satisfactory outcome. Conley [28] has recognised the disadvantages that accompany with multistage operations, namely, the negative psychological effects experienced by the patient losing his sexual apparatus. Wang et al. [29] used skin grafts for young patients who wished to remain fertile and flap reconstruction for older patients.

Interestingly, Sun and colleagues [30] assessed the physiological function of the testis in eight cases of scrotal skin graft coverage following trauma and infection. They showed that at 12 months, sperm volume, liquefaction time, counts and motility were all within normal range, and this was maintained for at least 24 months. The sperm examination in the present case showed normal values three months after the injury.

It has been shown that the most common complication after scrotal skin grafting is wound breakdown, which commonly occurs around the graft edges [31], but in the present case the graft take was close to $100 \%$ and there were no signs of infection or hematoma. There was one early disadvantage of this procedure which was painful erections in the early postoperative period but these painful episodes rarely continue. These painful erections are usually due to contractures at the penoscrotal and/or perineoscrotal junctions that may restrict the erectile function of the penis $[8,32,33]$. However, our patient reported painful erections due to cicatricial retraction of the grafted skin in the early post-operative period which subsided gradually by applying daily corticosteroid cream massage.

\section{Conclusion}

Genital avulsion injuries are rare surgical emergencies, which pose difficulties for the surgeon and can be devastating for the patient. Early surgical repair of the peno-scrotal skin loss is emphasized.

The present case of complete avulsion of penis and scrotum has been treated with a single staged procedure. The treatment technique involved is an STSG which gave good cosmetic and functional results.

\section{References}

[1] Mathur, R. K., Lahoti, B. K., Aggarwal, G., and Satsangi, B. 2010. "Degloving Injury to the Penis." Afr J Paediatr Surg (7): 19-21.

[2] Jha, A. K., Singh, S., and Gupta, S. 2012. "Split Thickness Skin Graft for Penile Skin Avulsion-Simple Solution for a Rare Injury." Surg Clin India (1): 1-3.

[3] Finical, S. J., and Arnold, P. G. 1999. "Care of the Degloved Penis and Scrotum: A 25-Year Experience." Plast Reconstr Surg 104 (7): 2074-8.

[4] Morey, A. F., Metro, M. J., Carney, K. J., Miller, K. S., and McAninch, J. W. 2004. "Consensus on Genitourinary Trauma: External Genitalia.” BJU Int. 94 (4): 507-15.

[5] Gencosmanoğlu, R., Bilkay, U., Alper, M., Gürler, T., and 
Cağdaş, A. 1995. "Late Results of Split-Grafted Penoscrotal Avulsion Injuries." J Trauma. 39 (6): 1201-3.

[6] Selikowitz, S. M. 1977. "Penetrating High-Velocity Genitourinary Injuries. Part I. Statistics Mechanisms, and Renal Wounds." Urology (9): 371-6.

[7] Paraskevas, K. I., Anagnostou, D., and Bouris, C. 2003. "An Extensive Traumatic Degloving Lesion of the Penis. A Case Report and Review of the Literature." Int Urol Nephrol (35): 523-7.

[8] Selvan, S. S., Alagu, G. S., and Gunasekaran, R. 2009. "Use of a Hypogastric Flap and Split-Thickness Skin Grafting for a Degloving Injury of the Penis and Scrotum: A Different Approach.” Indian J Plast Surg (42): 258-60.

[9] Kiffin, C., Porcelli, M., Prychyna, O., Pazmino, B., Pust, D., and Decostanza, J. 2012. "Penile Degloving Injury in an Adolescent with Congenital Hypothyroid." Case Rep Med 2012: 464670.

[10] Tripathi, F. M., Sinha, J. K., Bhattacharya, V., and Bariar, L. M. 1982. "Traumatic Avulsion of Penile and Scrotal Skin.” Br J Plast Surg 35 (3): 302-3.

[11] Kubacek, V. 1958. "Complete Avulsion of Skin of Penis and Scrotum." Br J Plast Surg (10): 25-31.

[12] Fu, Q. 2006. "Repair of Necrosis and Defects of Penile Skin with Autologous Free Skin Flap." Asian J Androl 8 (6): 741-4.

[13] Bickell, M., Beilan, J., Wallen, J., and Carrion, R. 2016. "Advances in Surgical Reconstructive Techniques in the Management of Penile, Urethral, and Scrotal Cancer." Urol Clin North Am 43 (4): 545-59.

[14] Mopuri, N., O’Connor, E. F., and Iwuagwu, F. C. 2016. "Scrotal Reconstruction with Modified Pudendal Thigh Flaps.” J Plast Reconstr Aesthet Surg (69): 278-83.

[15] Chen, S. Y., Fu, J. P., Chen, T. M., and Chen S. G. 2011. "Reconstruction of Scrotal and Perineal Defects in Fournier's Gangrene." J Plast Reconstr Aesthet Surg 64 (4): 528-34.

[16] Yao, H., Zheng, D., Wen, J., et al. 2014. "Reconstruction of Major Scrotal Defects by Anterolateral Thigh Flap." Cell Biochem Biophys (70): 1331-5.

[17] Brown, J. B., and Fryer, M. P. 1957. "Peno-Scrotal Skin Losses, Repaired by Implantation and Free Skin Grafting: Report of Known Normal Offspring (Preliminary Report on Total and Deep Losses)." Ann Surg 145 (5): 656-64.

[18] Aineskog, H., and Huss, F. 2016. "A Case Report of a Complete Degloving Injury of the Penile Skin.” Int J Surg Case Rep (29): 1-3.

[19] Campbell, R. M. 1957. "Dermatome Grafting of the Totally Denuded Testes." Plast Reconstr Surg (19):
509-13.

[20] Alton, J. D. 1963. "Complete Avulsion of the Scrotum." In Transactions of the Third International Congress of Plastic Surgery. Edited by T. R. Broadbent. Amsterdam: Excerpta Medica Foundation.

[21] Manchanda, R. L., Singh, R., and Keswani, R. K. 1967. "Traumatic Avulsion of the Scrotum and Penile Skin." $\mathrm{Br}$ J Plast Surg (20): 97-103.

[22] Khanna, N. N. 1969. "The Management of Avulsion Injuries of the Penis and Scrotum." Indian Journal of Plastic Surgery (2): 24.

[23] Zhao, J. C., Xian, C. J., Yu, J. A., and Shi, K. 2013. "Reconstruction of Infected and Denuded Scrotum and Penis by Combined Application of Negative Pressure Wound Therapy and Split-Thickness Skin Grafting." Int Wound J. 10 (4): 407-10.

[24] Maguiña, P., Palmieri, T. L., and Greenhalgh, D. G. 2003. "Split Thickness Skin Ggrafting for Rrecreation of the Scrotum Following Fournier's Gangrene.” Burns (29): 857-62.

[25] Rapp, D., Cohn, A., Gottlieb, L., et al. 2005. "Use of Tissue Expansion for Scrotal Sac Reconstruction after Scrotal Skin Loss.” Urology 65 (6): 1216-8.

[26] Maharaj, D., Naraynsingh, V., Perry, A., and Ramdasset, M. J. 2002. "The Scrotal Reconstruction Using the 'Singapore Sling'," Plast Reconstr Surg 110 (1): 203-5.

[27] Zanettini, L. A., Fachinelli, A., and Fonseca, G. P. 2005. "Traumatic Degloving Lesion of Penile and Scrotal Skin." Int Braz J Urol 31: 262-3.

[28] Conley, J. J. 1956. "A One-Stage Operation for the Repair of the Denuded Penis and Testicles." N Y State J Med 56 (19): 3014-6.

[29] Wang, D., Luo, Z., Sun, G., and Wei, Z. 2009. "Long-Term Prognosis of Free Skin-Grafted Penoscrotal Avulsion Injuries in Two Patients." J Plast Reconstr Aesthet Surg (62): 385-7.

[30] Sun, G., Wang, D., Wei, Z., Jin, W., and Deng, C. 2011. "Effect of Scrotal Reconstruction with Free Skin Graft on Spermatogenesis." Zhongguo Xiu Fu Chong Jian Wai Ke Za Zhi 25 (11): 1357-9.

[31] Lucas, J. 2017. "Scrotal Reconstruction and Testicular Prosthetics." Transl Androl Urol. 6 (4): 710-21.

[32] Wang, D., Zheng, H., and Deng, F. 2003. "Spermatogenesis after Scrotal Reconstruction." $\mathrm{Br} J$ Plast Surg 56 (5): 484-8.

[33] Demir, Y., Aktepe, F., Kandal, S., Sancaktar, N., and Turhan-Haktanir, N. 2011. "The Effect of Scrotal Reconstruction with Skin Flaps and Skin Grafts on Testicular Function.” Ann Plast Surg 68 (3): 308-13. 